\title{
Psychiatric morbidity and cervical cancer screening: a retrospective population-based case-cohort study
}

\author{
Michael Ouk BSc, Jodi D. Edwards PhD, Jessica Colby-Milley MSc, Alexander Kiss PhD, \\ Walter Swardfager PhD, Marcus Law MD MEd
}

Abstract

Background: Cervical cancer screening reduces disease-specific mortality. This study aimed to estimate whether bipolar disorder or schizophrenia is associated with disparities in cervical cancer screening rates.

Methods: This was a retrospective population-based matched case-cohort study of community-dwelling women aged 19-69 in Ontario using linked health administrative databases. We used odds ratios (ORs), hazards ratios and rate ratios (RRs) adjusted for demographic characteristics and relevant comorbidities to compare cervical cancer screening outcomes between women with a diagnosis of bipolar disorder or schizophrenia to women without that history matched on key demographic characteristics, between 2003 and 2015.

Results: In total, 1245457 women were identified for inclusion in the analyses, 119948 with a diagnosis of bipolar disorder or schizophrenia, and 1125509 without. Over a median follow-up duration of 12.5 years, women with the exposure were 36\% less likely to be screened (OR $0.64,95 \%$ confidence interval [Cl] 0.64-0.65) than those without, and they took longer to undergo screening (median $18.98 \mathrm{mo}$ v. $16.63 \mathrm{mo} ; \chi^{2}=3718.2, p<0.001$ ). They were also screened less frequently (median $6.16 \mathrm{yr}$ v. $4.69 \mathrm{yr}$ per screen; RR $0.85,95 \% \mathrm{Cl} 0.84-0.85)$. These effects were consistent after we excluded the 86475 women (6.9\%) with suspected major depressive disorder, and they were larger for the 59141 women (4.7\%) not attached to a family physician.

Interpretation: Women with bipolar disorder or schizophrenia were less likely to undergo cervical cancer screening, their screening was delayed, and they were screened at a lower rate compared to women without this psychiatric history. This practice gap suggests a need to further address barriers to screening, including access to a family physician, among women with bipolar disorder or schizophrenia.

T n Canadian women, mortality related to cervical cancer decreased by $60 \%$ between 1977 and 2006, largely attributable to provincial screening programs that facilitate detection and treatment of precancerous lesions. ${ }^{1,2}$ The 2005 Ontario Cancer Screening Program practice guideline recommended that cervical cytology screening be initiated within 3 years of first vaginal sexual activity. ${ }^{3}$ Screening was recommended every 3 years following 3 consecutive negative results of annual Papanicolaou tests. ${ }^{3}$ This guideline was updated in 2012, specifying that sexually active women aged more than 21 should be screened every 3 years and removing the criteria for negative results of 3 consecutive annual tests. ${ }^{4}$ Adherence has been moderate, with $65 \%$ of eligible Ontario women receiving a screen between 2009 and $2011 .^{5}$

Women with severe psychiatric conditions have a significantly higher rate of death from cervical cancer than those without these conditions despite comparable disease incidence. ${ }^{6}$ Previous reports show that women with common and severe psychiatric conditions, including bipolar disorder and schizophrenia, face barriers to screening uptake $7^{7,8}$ however, estimates have varied. ${ }^{1,9-11}$ Different selection criteria, classification methods, durations of follow-up or other factors may affect generalizability to the general population. ${ }^{9,11}$

Further population-based estimates are required to accurately quantify potential disparities in screening practices between women with and without psychiatric morbidity, and to promote the development of targeted interventions. ${ }^{6,9,11} \mathrm{In}$ the present study, we aimed to compare the likelihood and frequency of cervical cancer screening in community-dwelling women with and without a history of bipolar disorder or schizophrenia from the general population in Ontario.

Competing interests: Jessica Colby-Milley (formerly of Sunnybrook Research Institute) is now an employee of F. Hoffmann-La Roche (effective July 29, 2019). She receives full-time salary support from F. Hoffmann-La Roche. This role is unrelated to the present work. Her contributions to this manuscript were made before she commenced her role at F. Hoffmann-La Roche. No other competing interests were declared.

This article has been peer reviewed.

Correspondence to: Walter Swardfager,w.swardfager@utoronto.ca CMAJ Open 2020. DOI:10.9778/cmajo.20190184 


\section{Methods}

\section{Study design and data sources}

This was a retrospective matched case-cohort study using linked provincial administrative databases from Ontario, which has a population of about 14 million. ${ }^{12}$ All data were obtained from ICES, and women were identified across databases by means of unique encoded patient identifiers. The data set from this study is held securely in coded form at ICES. Access may be granted to those who meet prespecified criteria for confidential access, available at www.ices.on.ca/DAS.

We used data from the Canadian Institute for Health Information Discharge Abstract Database, National Ambulatory Care Reporting System and Ontario Health Insurance Plan (OHIP) database, which capture universally available government-funded coverage for all hospital and emergency department services, physician visits and diagnostic tests, combined with the Ontario Mental Health Reporting System Metadata, to identify bipolar disorder and schizophrenia diagnoses, using the International Classification of Diseases, 9th revision (ICD-9) and the International Statistical Classification of Diseases and Related Health Problems, 10th revision (ICD-10). ${ }^{13,14} \mathrm{We}$ obtained demographic information from the Ontario Registered Persons Database, and data on prescription history (for those aged $\geq 65$ yr) from the Ontario Drug Benefit Claims database. We used the Ontario Breast Screening Program database for outcome assessment to identify all cervical cancer screening procedures conducted during the study period.

These databases are subject to routine assessments of data quality. ${ }^{15}$ The Canadian Institute for Health Information provides facility-level reports for the Discharge Abstract Database, ${ }^{16}$ National Ambulatory Care Reporting System ${ }^{17}$ and Ontario Mental Health Reporting System, ${ }^{18}$ which contain complete or nearly complete data for Ontario. These reports identify data quality issues to improve data accuracy and comparability.

\section{Study population and exposure}

We identified and followed community-dwelling women aged 19-69 with a diagnosis of bipolar disorder or schizophrenia between 2003 and 2012 for the primary outcome of cervical cancer screening until the age of 70 (when cessation of screening was recommended in Ontario guidelines throughout the study period ${ }^{19}$ ), death, loss of OHIP eligibility or termination of follow-up on Dec. 31, 2015. Cohort entry at the age of 19 is consistent with the prevailing Ontario guideline ${ }^{19}$ and with other cohort studies that have defined entry between age 18 and 21.9,10,20,21 Exclusion criteria included an invalid OHIP number, and a history of cervical cancer or hysterectomy before July 1 of the year of cohort entry. The Ontario Health Insurance Plan is the taxpayer-funded government-operated health insurance plan that provides universal coverage of preventive and emergency physician and hospital services for people whose principal residence is in Ontario and who are present in Ontario for more than half of the days in a given year. Coverages can be lost if these eligibility criteria cease to be fulfilled.
The exposure was a prior diagnosis of bipolar disorder or schizophrenia, defined with the following algorithm: a discharge diagnosis of bipolar disorder or schizophrenia from the Discharge Abstract Database or Ontario Mental Health Reporting System using ICD-9 or ICD-10 diagnostic codes $^{13,14}$ (Appendix 1, Supplemental Table S1, available at www.cmajopen.ca/content/8/1/E134/suppl/DC1) within a 10 -year period before entry into the study cohort; an OHIP diagnostic billing code of bipolar disorder or schizophrenia (Appendix 1, Supplemental Table S1), with accompanying specialty code for psychiatry (19), within a 12-month period within 10 years before cohort entry; or 2 OHIP diagnostic billing codes of bipolar disorder or schizophrenia within a 12 -month period within 10 years before cohort entry.

We matched women with bipolar disorder or schizophrenia within each geographic Local Health Integration Network at a ratio of up to 10:1 to community-dwelling women from the general Ontario population $(n=1125509)$ on age $( \pm 2$ yr), Charlson Comorbidity Index score, income quintile, urban or rural residence, attachment to a family physician and Adjusted Diagnostic Group classification using greedy nearest-neighbour matching. ${ }^{22}$ Local Health Integration Networks are nonprofit community organizations defined by 14 separate geographic regions in Ontario. They oversee, regulate and fund public health care services and facilities, including hospitals, long-term care and mental health services, to improve patient access and the patient experience. Women without the exposure were matched only once with women who had the exposure; thus, owing to imbalances in the size of our subgroups, some exposed subjects could not be matched at an exact 10:1 ratio.

\section{Outcome}

The outcome was a documented screen for cervical cancer, defined with OHIP procedure code G365, E430 or G394.

\section{Statistical analysis}

We generated descriptive statistics to characterize the study cohort with respect to demographic and clinical variables. We compared baseline characteristics between women with and without the exposure using standardized differences and $\chi^{2}$ tests. We determined incidence rates of cervical cancer screening per 3 person-years to assess adherence to Ontario guideline for cervical cancer screening intervals. ${ }^{19}$

We used conditional logistic regression to estimate adjusted odds ratios (ORs) with $95 \%$ confidence intervals (CIs) of the likelihood of cervical cancer screening. We used Poisson regression to compare adjusted rate ratios (RRs) with $95 \%$ CIs of screening between exposed and unexposed women, and Cox proportional hazards regression to estimate adjusted hazard ratios (HRs) with $95 \%$ CIs for time to screening. We estimated these parameters using data within 3 years of cohort entry and for all available follow-up data. We used a log-rank test to compare time to first screen. Models were adjusted for certain potential clinical confounders that may be more likely to occur in women with psychiatric morbidity than in those without, or that may 
affect overall medical burden or propensity to receive cervical screening (Appendix 1, Supplemental Table S1).

To probe the influence of accessibility of health care resources, we performed subgroup analyses based on whether the woman was attached to a family physician. In this analysis, physician attachment was not used as a factor for matching.

Depressive disorders are common psychiatric comorbidities, ${ }^{23,24}$ and they have been independently associated with reduced use of health care services. ${ }^{25-28}$ However, inconsistent use of diagnostic codes for major depressive disorder can result in misclassification; ${ }^{29}$ therefore, we did not include suspected major depressive disorder in the exposure. In a sensitivity analysis, we excluded women with suspected major depressive disorder (ICD-9 code F296.2-296.36, ICD-10 code F33.x) to determine whether suspected major depressive disorder affected observed screening rates and associations.

We performed all statistical analyses using SAS, Version 14.2 (SAS Institute).

\section{Ethics approval}

This study was approved by the Research Ethics Board of Sunnybrook Health Sciences Centre. The details of this study are reported in accordance with STROBE and RECORD guidelines. $^{30,31}$

\section{Results}

Table 1 shows baseline characteristics for the whole cohort of Ontario women aged 19-69 on cohort entry ( $n=1245$ 457), the 119948 women with bipolar disorder or schizophrenia, and the 1125509 matched women without the exposure. Of the 119948 women with bipolar disorder or schizophrenia, 98368 $(82.0 \%)$ were matched 10:1, and 21580 (18.0\%) were matched between 1:1 and 9:1. The demographic characteristics of women with bipolar disorder or schizophrenia were similar to those of women without these diagnoses, although the prevalence of vascular diseases, diabetes, dyslipidemia, respiratory diseases, arthritis, osteoporosis, obesity, pelvic inflammatory diseases and polycystic ovary syndrome was significantly higher among exposed $\mathrm{v}$. unexposed women (Table 1).

\section{Likelihood, rate and time of screening}

Within the first 3 years of cohort entry, 719240 women (57.7\%) underwent cervical cancer screening, 60436 (50.4\%) of those with schizophrenia or bipolar disorder, and 658804 (58.5\%) of those without. The adjusted OR for having received 1 screen within the first 3 years was 0.71 (95\% CI $0.70-0.72$ ) (Table 2). The rate of screening within the first 3 years was 0.27 (95\% CI $0.27-0.28$ ) screens per 3 personyears among women with bipolar disorder or schizophrenia, and 0.36 (95\% CI 0.36-0.37) among those without (RR 0.80, 95\% CI 0.80-0.81) (Table 3 and Table 4). For comparison, the independent effects of other chronic diseases are presented in Table 4.

Throughout the entire follow-up period (median $12.5 \mathrm{yr}$ ), 958249 women $(76.9 \%)$ received at least 1 screen $(84228$
[70.2\%] in the exposure group and 874021 [77.7\%] in the group without exposure). The adjusted OR for having received at least 1 screen for women with schizophrenia or bipolar disorder relative to women without the exposure was 0.64 (95\% CI 0.64-0.65) (Table 2). The rate of screening was 0.49 (95\% CI $0.48-0.49$ ) screens per 3 person-years (i.e., on average, screening occurred every $6.16 \mathrm{yr}$ ) among women with bipolar disorder or schizophrenia, and 0.64 (95\% CI 0.64-0.64) (i.e., screening every $4.69 \mathrm{yr}$ ) among those without (RR 0.85, 95\% CI 0.84-0.85) (Table 3 and Table 4).

Among women who were screened at least once throughout the follow-up period, the rate of screening was lower for those with bipolar disorder or schizophrenia than for those without (HR 0.80, 95\% CI 0.80-0.80) (Table 5, Figure 1A). Specifically, women with the exposure were screened a median of 18.98 months after cohort entry, whereas those without the exposure were screened after a median of 16.63 months (log-rank test $\left.\chi^{2}=3718.22, p<0.001\right)$. The median length of time to either first screening after cohort entry or termination of follow-up was significantly longer for women with a history of schizophrenia or bipolar disorder $(30.70 \mathrm{mo})$ than for those without $(23.40 \mathrm{mo})(p<0.001)$.

\section{Physician attachment}

Among the 1186316 women (95.3\%) attached to a family physician, the adjusted OR for receiving 1 screen in the first 3 years was 0.72 (95\% CI $0.71-0.73$ ); throughout the entire follow-up period, it was 0.65 (95\% CI 0.64-0.66) (Appendix 1, Supplemental Table S2). In contrast, women not attached to a physician had a lower OR for screening over the first 3 years $(0.55,95 \%$ CI $0.51-0.59)$ and over the entire followup period $(0.55,95 \%$ CI 0.52-0.58) (Appendix 1, Supplemental Table S3). The RR of screening over all follow-up associated with bipolar disorder or schizophrenia was 0.85 (95\% CI $0.85-0.86$ ) for women attached to a family physician and 0.67 (95\% CI 0.64-0.70) for those not attached to a family physician (Appendix 1, Supplemental Table S4). The adjusted HR of screening was 0.81 (95\% CI 0.80-0.81) for attached women and 0.64 (95\% CI 0.61-0.67) for unattached women (Appendix 1, Supplemental Table S5).

Among women who were attached to a family physician, the rate of screening was 0.521 screens (95\% CI $0.517-0.524$ ) per 3 person-years (i.e., screening every $5.76 \mathrm{yr}$ ) for those with the exposure and 0.681 screens (95\% CI 0.680-0.683) (i.e., screening every $4.40 \mathrm{yr}$ ) for those without. Among women not attached to a family physician, the corresponding rates were 0.139 (95\% CI $0.133-0.145)$ (i.e., screening every $21.63 \mathrm{yr}$ ) and 0.210 (95\% CI 0.207-0.213) (i.e., screening every $14.29 \mathrm{yr})$.

\section{Sensitivity analysis among women without major depressive disorder comorbidity}

A total of 86475 women $(6.9 \%)$ in the overall cohort had a history of comorbid depressive illness (8516 [7.1\%] of those exposed and 78229 [7.0\%] of those unexposed) (Appendix 1, Supplemental Table S6). After these women were excluded, the likelihood of screening remained lower for women with 
Table 1: Baseline demographic and health characteristics of women in the general Ontario population aged 19-69 years between July 2003 and July 2012, comparing those with bipolar disorder or schizophrenia to those without

\begin{tabular}{|c|c|c|c|c|}
\hline \multirow[b]{2}{*}{ Characteristic } & \multicolumn{3}{|c|}{ Group; no. (\%) of women* } & \multirow[b]{2}{*}{$\begin{array}{c}\text { Standardized } \\
\text { difference† }\end{array}$} \\
\hline & $\begin{array}{c}\text { Overall } \\
n=1245457\end{array}$ & $\begin{array}{c}\text { Exposure } \\
n=119948\end{array}$ & $\begin{array}{c}\text { Matched } \\
n=1125509\end{array}$ & \\
\hline Age, yr, median (IQR) & $42(29-52)$ & $42(30-52)$ & $42(29-52)$ & 0.02 \\
\hline \multicolumn{5}{|l|}{ Income quintile } \\
\hline 1 (lowest) & $298115(23.9)$ & $29896(24.9)$ & $268219(23.8)$ & 0.03 \\
\hline 2 & $265181(21.3)$ & $25548(21.3)$ & $239633(21.3)$ & $<0.001$ \\
\hline 3 & $236935(19.0)$ & $22443(18.7)$ & $214492(19.1)$ & 0.01 \\
\hline 4 & $224190(18.0)$ & $21186(17.7)$ & $203004(18.0)$ & 0.01 \\
\hline 5 (highest) & $219010(17.6)$ & 20601 (17.2) & $198409(17.6)$ & 0.01 \\
\hline Missing & $2026(0.2)$ & $274(0.2)$ & $1752(0.2)$ & 0.02 \\
\hline \multicolumn{5}{|l|}{ Residence } \\
\hline Urban & $1131150(90.9)$ & $108389(90.3)$ & 1022761 (90.9) & 0.01 \\
\hline Rural & $113879(9.1)$ & $11496(9.6)$ & $102383(9.1)$ & 0.02 \\
\hline Missing & $428(0.03)$ & $63(0.1)$ & $365(0.03)$ & 0.01 \\
\hline \multicolumn{5}{|l|}{ Charlson Comorbidity Index score } \\
\hline 0 & $178386(14.3)$ & $24961(20.8)$ & $153425(13.6)$ & 0.19 \\
\hline 1 & $18447(1.5)$ & $3451(2.9)$ & $14996(1.3)$ & 0.11 \\
\hline 2 & $10749(0.9)$ & $1299(1.1)$ & $9450(0.8)$ & 0.02 \\
\hline$\geq 3$ & $8226(0.7)$ & $1002(0.8)$ & $7224(0.6)$ & 0.02 \\
\hline Missing & $1029649(82.7)$ & $89235(74.4)$ & $940414(83.6)$ & 0.23 \\
\hline \multicolumn{5}{|l|}{ Adjusted Diagnostic Group score } \\
\hline 0 & $32505(2.6)$ & $3011(2.5)$ & $29494(2.6)$ & 0.01 \\
\hline $1-3$ & $137524(11.0)$ & $12762(10.6)$ & $124762(11.1)$ & 0.01 \\
\hline $4-6$ & $318091(25.5)$ & $29369(24.5)$ & $288722(25.7)$ & 0.03 \\
\hline $7-9$ & $371691(29.8)$ & $34265(28.6)$ & $337426(30.0)$ & 0.03 \\
\hline$\geq 10$ & $385646(31.0)$ & $40541(33.8)$ & $345105(30.7)$ & 0.07 \\
\hline \multicolumn{5}{|l|}{ Comorbidities } \\
\hline Vascular diseases & $15082(1.2)$ & $1898(1.6)$ & $13184(1.2)$ & 153.04 \\
\hline Hypertension & $44240(3.6)$ & $3720(3.1)$ & $40520(3.6)$ & 78.72 \\
\hline Diabetes & $18251(1.5)$ & $2173(1.8)$ & $16078(1.4)$ & 110.18 \\
\hline Dyslipidemia & $4504(0.4)$ & $618(0.5)$ & $3886(0.4)$ & 86.90 \\
\hline Respiratory diseases & $8390(0.7)$ & $1740(1.4)$ & $6650(0.6)$ & 1197.55 \\
\hline Arthritis & $2547(0.2)$ & $302(0.2)$ & $2245(0.2)$ & 14.53 \\
\hline Crohn disease/ulcerative colitis & $2135(0.2)$ & $198(0.3)$ & $1937(0.2)$ & 0.31 \\
\hline Osteoporosis & $724(0.1)$ & $138(0.1)$ & $586(0.05)$ & 74.02 \\
\hline Obesity & $4646(0.4)$ & $942(0.8)$ & $3704(0.3)$ & 607.13 \\
\hline Pelvic inflammatory diseases & $870(0.1)$ & $115(0.1)$ & $755(0.1)$ & 12.87 \\
\hline Polycystic ovary syndrome & $126(0.01)$ & $27(0.02)$ & $99(0.01)$ & 20.15 \\
\hline \multicolumn{5}{|l|}{ Attached to family physician } \\
\hline Yes & $1186316(95.3)$ & $113722(94.8)$ & 1072594 (95.3) & 0.01 \\
\hline No & $59141(4.7)$ & $6226(5.2)$ & $52915(4.7)$ & 0.01 \\
\hline $\begin{array}{l}\text { Note: IQR = interquartile range. } \\
{ }^{*} \text { Except where noted otherwise. } \\
\text { t } \chi^{2} \text { test for comorbidities. For other charac } \\
\text { an estimate of the standard deviation. }\end{array}$ & ve calculated stand & ces through the & $\mathrm{n}$ the mean betweer & ups divided by \\
\hline
\end{tabular}


a psychiatric history than for those without a psychiatric history, both in the first 3 years (OR 0.72 , 95\% CI $0.71-0.73$ ) and over all available follow-up (OR 0.65, 95\% CI 0.64-0.66). Similarly, the adjusted HR for time to screening remained significantly lower $(0.81,95 \%$ CI $0.80-0.82$ ) (Table 5, Figure 1B).

\begin{tabular}{|c|c|c|}
\hline \multirow[b]{2}{*}{ Variable } & \multicolumn{2}{|c|}{ Adjusted OR $(95 \% \mathrm{Cl})^{*}$} \\
\hline & Within first 3 yr & All follow-up \\
\hline $\begin{array}{l}\text { Schizophrenia/bipolar } \\
\text { disorder }\end{array}$ & $0.71(0.70-0.72)$ & $0.64(0.64-0.65)$ \\
\hline Vascular diseases & $0.47(0.45-0.49)$ & $0.45(0.43-0.46)$ \\
\hline Hypertension & $0.92(0.90-0.94)$ & $0.92(0.90-0.95)$ \\
\hline Diabetes & $0.73(0.71-0.76)$ & $0.73(0.70-0.76)$ \\
\hline Dyslipidemia & $0.86(0.80-0.93)$ & $0.91(0.84-0.98)$ \\
\hline Respiratory diseases & $0.59(0.56-0.62)$ & $0.52(0.49-0.55)$ \\
\hline Arthritis & $0.76(0.70-0.84)$ & $0.86(0.78-0.95)$ \\
\hline $\begin{array}{l}\text { Crohn disease/ } \\
\text { ulcerative colitis }\end{array}$ & $0.75(0.68-0.83)$ & $0.77(0.68-0.86)$ \\
\hline Osteoporosis & $0.52(0.43-0.63)$ & $0.43(0.35-0.51)$ \\
\hline Obesity & $0.57(0.53-0.61)$ & $0.54(0.50-0.58)$ \\
\hline $\begin{array}{l}\text { Pelvic inflammatory } \\
\text { diseases }\end{array}$ & $0.66(0.56-0.77)$ & $0.58(0.49-0.69)$ \\
\hline $\begin{array}{l}\text { Polycystic ovary } \\
\text { syndrome }\end{array}$ & $0.93(0.63-1.38)$ & $1.04(0.60-1.80)$ \\
\hline
\end{tabular}

\section{Interpretation}

For women with bipolar disorder or schizophrenia, we report a $36 \%$ reduced likelihood of receiving at least 1 cervical cancer screen and a $15 \%$ lower RR of screening over the 12-year follow-up period, which translates into an overall adherence to triannual screening recommendations that was about $24 \%$ lower than that for women without this psychiatric history. The time to first screen after cohort entry was longer among women with these psychiatric conditions than among matched, unexposed cases, which further confirms a reduced propensity for cervical cancer screening. The magnitude of these disparities was greater for women not attached to a family physician.

Women with and without bipolar disorder or schizophrenia were matched for important demographic characteristics, and the models were adjusted for vascular and other clinical comorbidities that may directly affect complexity of care or screening rates. Although most comorbid chronic conditions studied were more prevalent among women with bipolar disorder or schizophrenia than among women without these conditions, their presence did not account for the disparity in screening. In the adjusted models, the independent effect of bipolar disorder or schizophrenia on the rate of screening was similar to those of respiratory diseases, arthritis, osteoporosis and obesity, smaller than that of vascular diseases, and larger than those of hypertension, diabetes and dyslipidemia.

The findings confirm and quantify a gap in use of preventive health services between Ontario women with and without severe psychiatric disorders, and they contribute to a growing body of literature that identifies mental health conditions as barriers to the uptake of cervical cancer screening. ${ }^{1,9,11,20,32,33}$ Notably, a study of women with and without schizophrenia in Manitoba identified a comparable magnitude of disparity (30\%) in the likelihood of receiving cervical screening. ${ }^{1}$ A conflicting investigation ${ }^{10}$ showed a higher frequency of cervical cancer screening among women with psychosis, bipolar disorder or

\begin{tabular}{|c|c|c|c|c|}
\hline Group; analytical period & No. of screens & Person-years & $\begin{array}{l}\text { Incidence per } \\
3 \text { person-years } \\
(95 \% \mathrm{Cl})\end{array}$ & $\begin{array}{c}\text { Average } \\
\text { years per } \\
\text { screen }\end{array}$ \\
\hline \multicolumn{5}{|l|}{ Overall } \\
\hline $3 \mathrm{yr}$ & 719240 & 6071289 & $0.355(0.355-0.356)$ & 8.45 \\
\hline All follow-up & 958249 & 4615795 & $0.623(0.622-0.624)$ & 4.82 \\
\hline \multicolumn{5}{|c|}{ Schizophrenia/bipolar disorder } \\
\hline $3 \mathrm{yr}$ & 60436 & 661669 & $0.274(0.272-0.276)$ & 10.95 \\
\hline All follow-up & 84288 & 519348 & $0.487(0.483-0.490)$ & 6.16 \\
\hline \multicolumn{5}{|l|}{$\begin{array}{l}\text { No schizophrenia/bipolar } \\
\text { disorder }\end{array}$} \\
\hline $3 \mathrm{yr}$ & 658804 & 5409619 & $0.365(0.364-0.366)$ & 8.22 \\
\hline All follow-up & 874021 & 4096447 & $0.640(0.639-0.641)$ & 4.69 \\
\hline
\end{tabular}


Table 4: Rate ratios from Poisson regression of rates of cervical cancer screening within the first 3 years and over all available follow-up (2003-2015) in women with schizophrenia or bipolar disorder relative to women without the exposure

Adjusted RR $(95 \% \mathrm{Cl})^{*}$

\begin{tabular}{|lcc|}
\hline \multirow{2}{*}{ Variable } & \multicolumn{2}{c|}{ Adjusted RR $(95 \% \mathrm{Cl})^{*}$} \\
\cline { 2 - 3 } $\begin{array}{l}\text { Schizophrenia/bipolar } \\
\text { disorder }\end{array}$ & $0.80(0.80-0.81)$ & $0.85(0.84-0.85)$ \\
\hline Vascular diseases & $0.66(0.65-0.67)$ & $0.75(0.74-0.76)$ \\
\hline Hypertension & $0.95(0.94-0.95)$ & $0.96(0.96-0.97)$ \\
\hline Diabetes & $0.87(0.86-0.88)$ & $0.91(0.90-0.92)$ \\
\hline Dyslipidemia & $0.89(0.86-0.92)$ & $0.91(0.89-0.93)$ \\
\hline Respiratory diseases & $0.81(0.80-0.83)$ & $0.86(0.85-0.87)$ \\
\hline Arthritis & $0.82(0.79-0.84)$ & $0.87(0.85-0.89)$ \\
\hline $\begin{array}{l}\text { Crohn disease/ } \\
\text { ulcerative colitis }\end{array}$ & $0.94(0.91-0.97)$ & $0.96(0.94-0.98)$ \\
\hline $\begin{array}{ll}\text { Osteoporosis } \\
\text { Obesity }\end{array}$ & $0.76(0.70-0.82)$ & $0.82(0.78-0.87)$ \\
\hline $\begin{array}{l}\text { Pelvic inflammatory } \\
\text { diseases }\end{array}$ & $0.79(0.77-0.81)$ & $0.85(0.83-0.86)$ \\
\hline $\begin{array}{l}\text { Polycystic ovary } \\
\text { syndrome }\end{array}$ & $1.03(0.91-1.16)$ & $1.03(0.97-1.10)$ \\
\hline $\begin{array}{l}\text { Note: Cl = confidence interval, RR } \text { Rate ratio. } \\
\text { *Adjusted for comorbidities included in table. }\end{array}$ & $0.96(0.92-0.99)$ \\
\hline
\end{tabular}

Table 5: Hazard ratios from Cox proportional hazards regression for time to first cervical cancer screen in the complete cohort and in a subgroup with major depressive disorder excluded

Adjusted HR $(95 \% \mathrm{Cl})^{*}$

\begin{tabular}{|llc|}
\hline & \multicolumn{2}{c|}{ Adjusted HR (95\% Cl)* } \\
\cline { 2 - 3 } Variable & $\begin{array}{c}\text { Subgroup excluding } \\
\text { major depressive } \\
\text { disorder }\end{array}$ \\
\hline $\begin{array}{l}\text { Schizophrenia/bipolar } \\
\text { disorder }\end{array}$ & $0.80(0.80-0.81)$ & $0.81(0.80-0.82)$ \\
\hline Vascular diseases & $0.61(0.60-0.63)$ & $0.62(0.60-0.64)$ \\
\hline Hypertension & $0.94(0.93-0.96)$ & $0.94(0.93-0.95)$ \\
\hline Diabetes & $0.82(0.80-0.84)$ & $0.82(0.81-0.84)$ \\
\hline Dyslipidemia & $0.88(0.84-0.92)$ & $0.87(0.83-0.92)$ \\
\hline Respiratory diseases & $0.73(0.70-0.75)$ & $0.72(0.70-0.75)$ \\
\hline Arthritis & $0.85(0.80-0.90)$ & $0.84(0.79-0.90)$ \\
\hline $\begin{array}{l}\text { Crohn disease/ } \\
\text { ulcerative colitis }\end{array}$ & $0.85(0.80-0.90)$ & $0.85(0.80-0.90)$ \\
\hline Osteoporosis & $0.63(0.55-0.72)$ & $0.63(0.55-0.72)$ \\
\hline Obesity & $0.68(0.65-0.71)$ & $0.69(0.66-0.72)$ \\
\hline $\begin{array}{l}\text { Pelvic inflammatory } \\
\text { diseases }\end{array}$ & $0.81(0.73-0.89)$ & $0.81(0.73-0.89)$ \\
\hline $\begin{array}{l}\text { Polycystic ovary } \\
\text { syndrome }\end{array}$ & $0.95(0.76-1.18)$ & $0.93(0.73-1.16)$ \\
\hline $\begin{array}{l}\text { Note: Cl = confidence interval, HR = hazard ratio. } \\
\text { *Adjusted for comorbidities included in table. }\end{array}$ & \\
\hline
\end{tabular}

mania; however, those cross-sectional data were drawn from an independent insurer-paid model with exclusively low-income participants, which suggests that demographic characteristics and care model may affect screening rates.

Future directions for research include identifying and validating other actionable barriers that could be targeted to diminish the observed disparity. Prior studies have suggested that both patient and physician efforts to address acute psychiatric symptoms may supersede indications for preventive procedures. ${ }^{34,35}$ For women with psychosis-related delusions and hallucinations, the purpose of screening or treatment may be unclear, and fear or distrust toward primary care physicians and invasive procedures may result in avoidance of screening. ${ }^{7,8,20}$ The values and attitudes of physicians can also play a role, and stigma can translate into disparities in screening and other services. ${ }^{33,36}$

Evidence suggests that distributing targeted letters of invitation, offering telephone counselling, addressing financial barriers and focusing on continuity of care may improve uptake, ${ }^{32,37}$ but the effectiveness of these methods has yet to be investigated specifically in women with severe psychiatric disorders. ${ }^{38}$ In the present study, lack of attachment to a family physician was associated with a much larger effect of psychiatric morbidity on screening rates, identifying a group at particularly high risk and highlighting the importance of access to primary care. Future studies might stratify analyses based on other sociodemographic factors to identify subgroups that may be at the highest risk and to identify specific barriers to address to mitigate underuse.

There may be a role for family physicians to audit their practices to identify their rate of cervical cancer screening in this defined population and to adopt quality-improvement plans to target this screening disparity when identified. Psychiatrists, social workers and mental health professionals might encourage patients to visit family physicians for screening and advocate to improve primary care access.

\section{Limitations}

The population-based nature, use of public health records and relatively long follow-up are notable strengths of the present work. We also acknowledge several limitations. Ontario residents have universal access to physician and hospital care under OHIP, which limits the generalizability of our findings to populations under other models of care; however, the results provide estimates that are less likely to reflect differences in insurance availability, unemployment and socioeconomic status. The current analysis matched on Local Health Integration Network to further account for geographic and, to some extent, socioeconomic barriers, but we were unable to control for several individual sociodemographic factors that have been linked to underuse of health care services, including household income, cultural differences and comorbid substance use disorders. ${ }^{39}$ In addition, although the specific algorithm used to ascertain the exposure in this study was not validated previously, the method is supported by prior work. ${ }^{40-42}$

We did not ascertain estimates for major depressive disorder alone; however, the observed differences associated with 
A

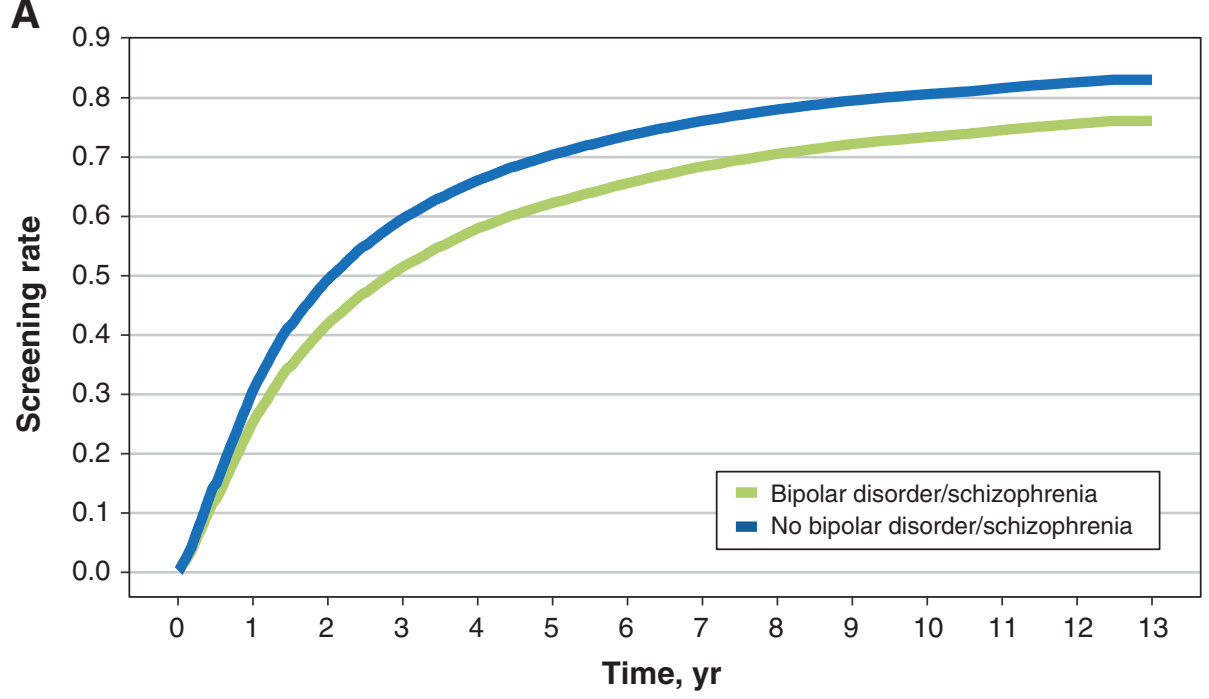

B

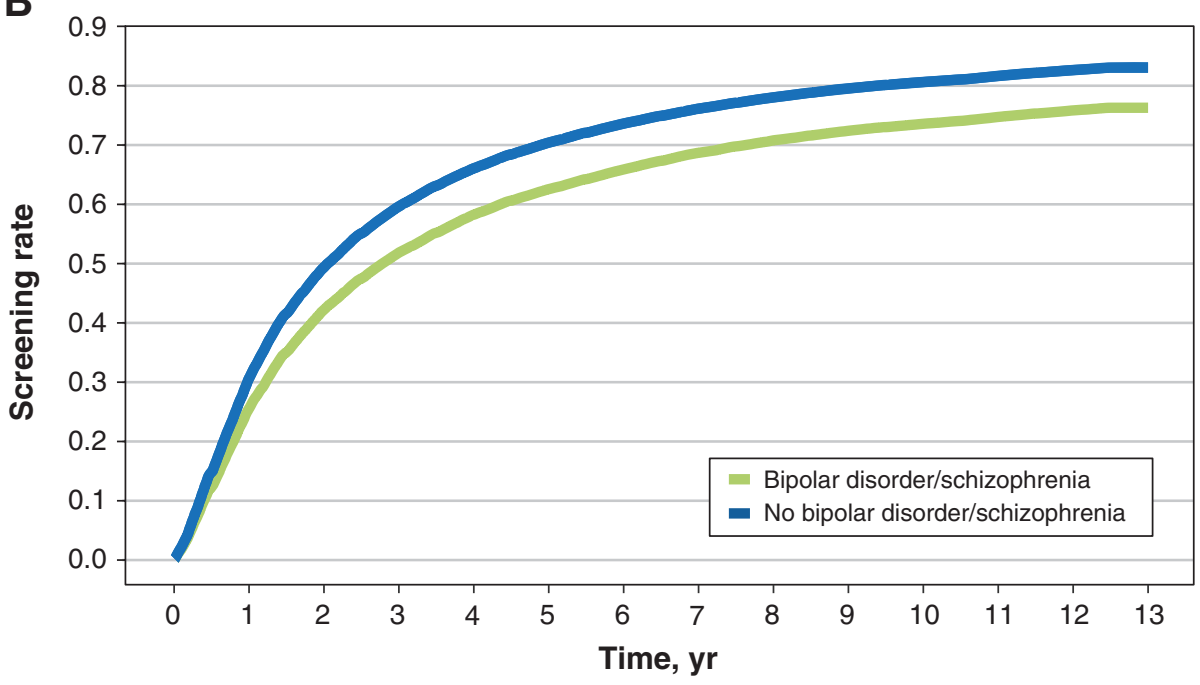

Figure 1: Cumulative incidence curve for cervical cancer screening over the follow-up period (2003-2015) for all women with and without bipolar disorder or schizophrenia (A) and excluding women with major depressive disorder (B). Log-rank test $p<0.001$.

bipolar disorder or schizophrenia remained consistent in sensitivity analyses that excluded women with a diagnostic code for major depressive disorder.

Finally, as a general limitation of studies using public health records, it is possible that not all people with the exposure were identified; however, potential misclassification of some exposed women as unexposed would result in conservative estimates that underestimate the discrepancies identified.

\section{Conclusion}

The likelihood of cervical cancer screening was 36\% lower among Ontario women with bipolar disorder or schizophrenia than among carefully matched women without these conditions, and this disparity was larger among those who were not attached to a physician. Because screening is critical for the early detection and treatment of cervical cancer, this disparity is likely to result in increased morbidity and mortality, which warrants the attention of patients, their care providers and other health care professionals.

\section{References}

1. Martens PJ, Chochinov HM, Prior HJ, et al. Are cervical cancer screening rates different for women with schizophrenia? A Manitoba population-based study. Schizophr Res 2009;113:101-6.

2. Kitchener HC, Castle PE, Cox JT. Chapter 7: Achievements and limitations of cervical cytology screening. Vaccine 2006;24(Suppl 3):S3/63-70.

3. McLachlin CM, Mai V, Murphy J, et al.; Members of the Cervical Screening Guidelines Development Committee of the Ontario Cervical Screening Program and the Gynecology Cancer Disease Site Group of Cancer Care Ontario. Cervical screening: practice guideline report. Toronto: Cancer Care Ontario; 2005. Available: http://www.ontla.on.ca/library/repository/mon/11000/253739.pdf (accessed 2020 Jan. 29). 
4. Murphy J, Kennedy EB, Dunn S, et al. Cervical screening: a guideline for clinical practice in Ontario. 7 Obstet Gynaecol Can 2012;34:453-8.

5. Cervical cancer screening rates below provincial target and vary with neighbourhood income. Toronto: Cancer Care Ontario; 2014. Available: https:// www.cancercareontario.ca/en/cancer-facts/cervical-cancer-screening (accessed 2019 Dec. 20)

6. Kisely S, Crowe E, Lawrence D. Cancer-related mortality in people with mental illness. 7AMA Psychiatry 2013;70:209-17.

7. Owen C, Jessie D, De Vries Robbé M. Barriers to cancer screening amongst women with mental health problems. Health Care Women Int 2002;23:561-6.

8. Kahn LS, Fox CH, Krause-Kelly J, et al. Identifying barriers and facilitating factors to improve screening mammography rates in women diagnosed with mental illness and substance use disorders. Women Health 2005;42:111-26.

9. Howard LM, Barley EA, Davies E, et al. Cancer diagnosis in people with severe mental illness: practical and ethical issues. Lancet Oncol 2010;11:797-804.

10. Abrams MT, Myers CS, Feldman SM, et al. Cervical cancer screening and acute care visits among Medicaid enrollees with mental and substance use disorders. Psychiatr Serv 2012;63:815-22.

11. James M, Thomas M, Frolov L, et al. Rates of cervical cancer screening among women with severe mental illness in the public health system. Psychiatr Serv 2017;68:839-42.

12. Population estimates on fuly 1st, by age and sex [population by year, by province and territory (number)]. Ottawa: Statistics Canada; 2017. Available: www. statcan.gc.ca/tables-tableaux/sum-som/101/cst01/demo02a-eng.htm (accessed 2018 Oct. 18)

13. International classification of diseases: [9th] ninth revision, basic tabulation list with alphabetic index. Geneva: World Health Organization, 1978.

14. ICD-10: International statistical classification of diseases and related bealth problems: tenth revision, 2nd ed. Geneva: World Health Organization, 2004.

15. Iron K, Manuel DG. Quality assessment of administrative data (QuAAD): an opportunity for enhancing Ontario's bealth data - ICES investigative report. Toronto: ICES; 2007.

16. Discharge Abstract Database open-year data quality test specifications, 2018-2019. Ottawa: Canadian Institute for Health Information; 2019. Available: https:// www.cihi.ca/sites/default/files/document/dad-2018-2019-oydq-specs-en03 pc. pdf (accessed 2020 Jan. 12).

17. Data quality documentation, National Ambulatory Care Reporting System, 20172018. Ottawa: Canadian Institute for Health Information; 2018. Available: https://www.cihi.ca/sites/default/files/document/current-year-information-nacrs -2017-2018-en-web.pdf (accessed 2020 Jan. 12).

18. Ontario Mental Health Reporting System: data quality documentation, 2017-2018. Ottawa: Canadian Institute for Health Information; 2018. Available: https:// www.cihi.ca/sites/default/files/document/omhrs-data-quality-external-report -2017-2018-en-web.pdf (accessed 2020 Jan. 12).

19. Murphy J, Kennedy E, Dunn S, et al. Cervical screening. Toronto: Cancer Care Ontario; 2011

20. Tilbrook D, Polsky J, Lofters A. Are women with psychosis receiving adequate cervical cancer screening? Can Fam Physician 2010;56:358-63.

21. Kouyoumdjian FG, McConnon A, Herrington ERS, et al. Cervical cancer screening access for women who experience imprisonment in Ontario, Canada. 7AMA Netw Open 2018;1:e185637.

22. Bergstralh EJ, Kosanke JL. Computerized matching of cases to controls. Rochester (MN): Mayo Foundation; 1995.

23. Buckley PF, Miller BJ, Lehrer DS, et al. Psychiatric comorbidities and schizophrenia. Schizophr Bull 2009;35:383-402.

24. Gozdzik-Zelazny A, Borecki L, Pokorski M. Depressive symptoms in schizophrenic patients. Eur 7 Med Res 2011;16:549-52.

25. Lo C, Calzavara A, Kurdyak P, et al. Depression and use of health care services in patients with advanced cancer. Can Fam Physician 2013;59:e168-74.

26. Beaulieu T, Ti L, Milloy MJ, et al. Major depressive disorder and access to health services among people who use illicit drugs in Vancouver, Canada. Subst Abuse Treat Prev Policy 2018;13:3.

27. Patten SB, Williams JV, Lavorato DH, et al. The effect of major depression on participation in preventive health care activities. BMC Public Health 2009;9:87.

28. Price MA, Butow PN, Charles M, et al. Predictors of breast cancer screening behavior in women with a strong family history of the disease. Breast Cancer Res Treat 2010;124:509-19.

29. Zimmermann P, Brückl T, Nocon A, et al. Heterogeneity of DSM-IV major depressive disorder as a consequence of subthreshold bipolarity. Arch Gen Psychiatry 2009;66:1341-52.

30. von Elm E, Altman DG, Egger M, et al. The Strengthening the Reporting of Observational Studies in Epidemiology (STROBE) Statement: guidelines for reporting observational studies. 7 Clin Epidemiol 2008;61:344-9.

31. Benchimol EI, Smeeth L, Guttmann A, et al. The REporting of studies Conducted using Observational Routinely-collected health Data (RECORD) Statement. PLoS Med 2015;12:e1001885.
32. Woodhead C, Cunningham R, Ashworth M, et al. Cervical and breast cancer screening uptake among women with serious mental illness: a data linkage study. BMC Cancer 2016;16:819.

33. Lofters AK, Mark A, Taljaard M, et al. Cancer screening inequities in a time of primary care reform: a population-based longitudinal study in Ontario, Canada. BMC Fam Pract 2018;19:147.

34. Chocontá-Piraquive LA, Alvis-Guzman N, De la Hoz-Restrepo F. How protective is cervical cancer screening against cervical cancer mortality in developing countries? The Colombian case. BMC Health Serv Res 2010;10:270.

35. Ross LE, Vigod S, Wishart J, et al. Barriers and facilitators to primary care for people with mental health and/or substance use issues: a qualitative study. $B M C$ Fam Pract 2015;16:135.

36. Clifton A, Burgess C, Clement S, et al. Influences on uptake of cancer screening in mental health service users: a qualitative study. BMC Health Serv Res 2016;16:257.

37. Black ME, Yamada J, Mann V. A systematic literature review of the effectiveness of community-based strategies to increase cervical cancer screening. Can $\mathcal{F}$ Public Health 2002;93:386-93.

38. Barley EA, Borschmann RD, Walters $\mathrm{P}$, et al. Interventions to encourage uptake of cancer screening for people with severe mental illness. Cochrane Database Syst Rev 2016;(9):CD009641.

39. Kelly DL, Myers CS, Abrams MT, et al. The impact of substance abuse on osteoporosis screening and risk of osteoporosis in women with psychotic disorders. Osteoporos Int 2011;22:1133-43.

40. Kurdyak P, Lin E, Green D, et al. Validation of a population-based algorithm to detect chronic psychotic illness. Can 7 Psychiatry 2015;6:362-8.

41. Kurdyak P, Vigod S, Duchen R, et al. Diabetes quality of care and outcomes: comparison of individuals with and without schizophrenia. Gen Hosp Psychiatry 2017;46:7-13

42. Mei-Dan E, Ray JG, Vigod SN. Perinatal outcomes among women with bipolar disorder: a population-based cohort study. Am 7 Obstet Gynecol 2015;212:367.e1-8.

Affiliations: Hurvitz Brain Sciences Program (Ouk, Colby-Milley, Swardfager), Sunnybrook Research Institute, University of Toronto; Departments of Pharmacology \& Toxicology (Ouk, Swardfager) and Family \& Community Medicine (Law), University of Toronto, Toronto, Ont.; University of Ottawa Heart Institute (Edwards); School of Epidemiology and Public Health (Edwards), University of Ottawa, Ottawa, Ont.; ICES (Kiss), Toronto, Ont.

Contributors: Michael Ouk and Jodi Edwards contributed equally to the work. Michael Ouk, Jodi Edwards, Alexander Kiss, Walter Swardfager and Marcus Law contributed to the study conception and design. Analysts at ICES analyzed the data under the direction of Michael Ouk, Walter Swardfager and Jodi Edwards. Michael Ouk, Jodi Edwards, Jessica ColbyMilley, Walter Swardfager and Marcus Law interpreted the data and revised the manuscript critically for important intellectual content. Michael Ouk drafted the manuscript. All of the authors approved the final version to be published and agreed to be accountable for all aspects of the work.

Funding: This study was funded by the Innovations Strengthening Primary Healthcare Research Program (Applied Health Research Question funding), Ontario Ministry of Health and Long-Term Care.

Acknowledgements: The authors gratefully acknowledge support from the Department of Psychiatry, Sunnybrook Health Sciences Centre, and the Department of Pharmacology \& Toxicology, University of Toronto.

Disclaimer: This study was supported by ICES, which is funded by an annual grant from the Ontario Ministry of Health and Long-Term Care (MOHLTC). The opinions, results and conclusions reported in this article are those of the authors and are independent from the funding sources. No endorsement by ICES or the Ontario MOHLTC is intended or should be inferred. Views expressed do not necessarily reflect those of the Province of Ontario.

Supplemental information: The full data set creation plan and underlying analytic code are available from the authors on request, with the understanding that the programs may rely on coding templates or macros that are unique to ICES. For reviewer comments and the original submission of this manuscript, please see www.cmajopen.ca/content/8/1/E134/ suppl/DC1. 